\title{
Atom-at-a-Time Radiochemical Separations of the Heaviest Elements: Lawrencium Chemistry
}

D.C. Hoffman, R.A. Henderson, K.E. Gregoric. D.A. Bennett, R.M. Chasteler, C.M. Gannett, H.L. Hall, D.M. ee, M.J. Nurmia, S. Ca i, * R. Agarwal, A.W. Charlop, Y.Y. Chu

Nuclear Science Division

Lawrence Berkeley Laboratory

University of California

Berkeley, California 94720

and

\section{R.J. Silva}

Nuclear Chemistry Division

Lawrence Livermore National Laboratory

$$
\text { P.0. Box } 808
$$

Livermore, California 94550

\author{
April 1987
}

*Institute of Atomic Energy, P.o. Box 275, Beijing, People's Republic of China.

This work was supported by the Director, Office of Energy Research, Division of Nuclear Physics of the Office of High Energy and Nuclear Physics of the U.S. Department of Energy under Contract DE-ACO3-76SF00098.

\section{MASTER}


D. C. Hoffman, R. A. Henderson, K. E. Gregorich, D. A. Bennett, R. M. Chasteler, C. M. Gannett, H. L. Hall, D. M. Lee, M. J. Nurnia, S. Cai,* R. Agarwal, A. W. Charlop, Y. Y. Chu

$$
\begin{gathered}
\text { Nuclear Science Division } \\
\text { Lawrence Berkeley Laboratory } \\
\text { Berkeley, CA } 94720
\end{gathered}
$$

$$
\text { R. J. Silva }
$$

Nuclear Chemistry Division, Lawrence Livermore National Laboratory P. 0. Box 809

Livermore, CA 94550

The isotope ${ }^{260} \mathrm{Lr}$ produced in reactions of ${ }^{18} 0$ with $249_{B K}$ was used to perform chemical experiments on lawrencium to learn more about its chemical properties. These experiments involved extractions with thenoyl trifluoroacetate (TTA), ammonium alpha-hydroxyisobutyrate (HIB) elution from a cat.n exchange res in column, and reverse-phase chromatography us ing hydrogen di(2-ethylhexyl) orthophosphoric acid (HOEHP) to investigate the cherical properties of Lr. The results from the HIB elutions also give information about the ionic radius of $\operatorname{Lr}(I I I)$ which was found to elute very close to $\mathrm{Er}$. An attempt to reduce $\operatorname{Lr}(\mathrm{III})$ was also made.

\section{INTROOUCTION}

Studies of the chemical properties of the elements above fermium are very difficult because these elements must be produced at accelerators and must be performed with isotopes having very short half-lives and available in quantities of only a few atoms at a time. This necessitates devising very fast and efficient radiochemical procedures. In addition, if reliable information concerning chemical properties is to be obtained, methods in which each of the available 
atoms is equilibrated rapidly through many reactions are normally required.. Techniques such as ion exchange, solvent extraction, and gas chromatography can often be used. A classic example of such a study is the determination ${ }^{2}$ of the No(II)-No(III) potential by silva et al. The 3-minute ${ }^{255}$ Nio isotope produced from the ${ }^{244} \mathrm{Pu}\left({ }^{16} 0,5 n\right)$ reaction was used. The distinction between $N$ (II) and No(III) was made on a few atoms at a time basis by using a column chromatographic technique. The standard potential was estimated from a comparison of the behavior of nobelium with the behavior of tracer quantities of other radionuclides of known standard potentials.

Studies of the chemical properties of the heaviest actinides and comparison with the properties of the lanthanides are of particular interest because they help assess the influence of relativistic effects. ${ }^{3}$ These cause a stabilization of the $s$ and $p$ orbitals in the actinides. By analogy with lutetium, the last of the lanthanide series, which has an electronic structure of $\left[X_{e}\right] 4 f^{14} 5 d^{1} 6 s^{2}$, the structure of lawrencium would be expected to be $[R n] 5 f^{14} 6 d^{1} 7 s^{2}$. However, because of relativistic effects, Brewer ${ }^{3}$ predicted the configuration would be $[R n] 5 f^{14} 7 s^{2} 7 p^{1}$ and Dirac-Fock calculations ${ }^{4}$ confirm this prediction. Furthermore, the $7 s^{2}$ might be stabilized to the extent that only the $7 p_{1 / 2}$ electron could be removed in the presence of suitable reducing agents, resulting in the production of $\mathrm{Lr}$ in the $1^{+}$ oxidation state.

Recently, we have undertaken experiments to deduce the ionic radius of lawrencium (element 103) by determining its elution position from a cation-exchange resin column relative to the trivalent rare earths and other trivalent actinides for which the ionic radii ${ }^{5-7}$ are known. Earlier extraction studies ${ }^{8}$ using the $26-\mathrm{s}{ }^{256}$ Lr have shown that Lr(III) is the most stable oxidation state in aqueous solution and that 
Lr completes the actinide series as predicted by Seaborg ${ }^{9}$ in 1945 . The elution positions from cation exchange res in columns with ammonium alpha-hydroxyisobutyrate (HIB) have also been determined 10,11 for the trivalent rare earths and for the actinides through mendelevium (element 101). These elements are eluted in order of the ir ionic radii, those with the smallest radii being eluted first. Although $260_{\mathrm{Lr}}$, an 8.03-MeV alpha-emitting isotope with a half-life of $3.0 \pm 0.5 \mathrm{~m}$, was discovered by Eskola et a.$^{12}$ in 1971, no further chemical experiments were parformed on Lr until our present studies.

\section{I1. EXPER IMENTAL}

A. Production of $260 \mathrm{Lr}$

The $3-m{ }^{260} \mathrm{Lr}$ was produced via the reaction ${ }^{249} \mathrm{BK}\left({ }^{18} 0, \alpha 3 n\right)$ at the LBL 88-Inch Cyclotron. Targets of $\mathrm{Bk}_{2} \mathrm{O}_{3}$ containing about 0.9 $\mathrm{mg} / \mathrm{cm}^{2}$ of ${ }^{249} \mathrm{Bk}$ were prepared by electrodeposition ${ }^{13}$ with a diameter of $6 \mathrm{~mm}$ on $2.75 \mathrm{mg} / \mathrm{cm}^{2}$ Be foil. They were irradiated with $117-\mathrm{MeV}{ }^{18} 0^{5+}$ projectiles resulting in incident energies on target of i02-MeV with intensities of about 0.5 puA. A stream of helium was passed over crystalline $\mathrm{KCl}$ kept at about $650 \mathrm{C}^{0}$ in a quartz tube before being fed into the target recoil chamber where the pressure of He was about 1.3 bar. The recoiling reaction products attach to the $\mathrm{KCl}$ aerosol and are transported via the pressurized He gas system through a capillary to a collection chamber several meters away where they are collected on a metallic foil. Typically, reaction products were collected for 6 to 10 minutes and then chemically processed.

\section{B. Chemical procedures}

In order to verify that the 3-m activity was indeed properly assigned to $L r$, extractions with $0.1 \mathrm{M}$ thenoyl trifluoroacetate (TTA) in methyl isobutyl ketone (MIBK) were performed. The $K C 1$ depos it was 
dissolved in a buffer solution of monochloroacetic acid or acetic acid adjusted to $\mathrm{pH}$ ranges of 1.86 to 5.5. Extractions with TTA from buffer solutions of different $\mathrm{pH}$ were performed. The organic phase was dried on a Pt plate and alpha counted. The entire procedure required about three minutes.

Reduction of $L r$ was also attempted. A reverse-phase chromatographic column ${ }^{14}(2-\mathrm{mm}$ i.d. $\times 5-\mathrm{cm}$ long) consisting of hydrogen di(2-ethylhexyl)orthosphophoric acid (HDEHP) on hydrophobic celite (50-75 micron diameter particles) was used to sorb trivalent and higher oxidation state species from $0.3 \mathrm{M} \mathrm{HNO}_{3}$. The lower valent species and $\mathrm{Ac}^{3+}$ were completely removed by washing with $0.3 \mathrm{M} \mathrm{HCl}$. In the reduction experiments, $0.06 \mathrm{M} \mathrm{NH}_{2} \mathrm{OH} \bullet \mathrm{HCl}$ in $0.3 \mathrm{M} \mathrm{HCl}$ was passed through the column at a temperature of about $80^{\circ} \mathrm{C}$ in an attempt to reduce $\mathrm{Lr}^{3+}$ to a lower oxidation state which would then be removed from the column. Trivalent actinides can be quickly eluted from the column with $3 \mathrm{M} \mathrm{HCl}$ leaving tetravalent and higher oxidation state species on the column. Thus appropriate combinations of these separations can be used to distinguish between $1^{+}$or $2^{+}, 3^{+}$, and $4^{+}$oxidation states of heavy actinides. In other experiments, the reaction products, together with the appropriate rare earth tracers, were taken up in $0.05 \mathrm{M} \mathrm{HCl}$ and sorbed on a $2-\mathrm{rm}$ i.d. $\times$ 4.5-cm long, 10 micron particle size, Dionex cation exchange res in column. The actinides and lanthanides were eluted with $0.05 \mathrm{M}$ ammonium alpha-hydroxyisobutyrate adjusted to $\mathrm{pH} 4.47$. The fractions were collected dropwise on Pt foils, evaporated to dryness, flamed, and alpha counted. The plates were later subjected to gamma-spectral analys is to determine the elution positions of the added rare earth tracer pairs, yb and $\mathrm{Er}$, and Tm and Ho. About 6 minutes were required for separation before alpha spectroscopic measurements could begin. 


\section{Data analys is}

Alpha spectra were measured with $300 \mathrm{~mm}^{2} \mathrm{si}(\mathrm{Au})$ surface barrier detectors. Data acquisition and analys is were performed using our Realtime data Acquisition and Graphics System (RAGS). The signals from the ADC's are taken into a Standard Engineering CAMAC interface to a Digital Equipment Corporation LSI $11 / 73$ computer and the detector number, time, and channel number (energy) for each event are stored on magnetic tape... Th is 1 ist mode storage allows versatile off-line data analys is, including histograming and time-correlation analys is. Using this system we can search for alpha-time correlations from successive alpha decays between mother, daughter, etc., in a genetic sequence. In this way, 8.03-MeV alphas arising from decay of $2.2-\mathrm{m}^{223} \mathrm{AC}$ (produced from reactions of ${ }^{18} 0$ with possible traces of ${ }^{208} \mathrm{~Pb}$ in the target) via the decay chain shown in Fig. 1 could be distinguished from the $8.03-\mathrm{MeV}$ alphas from ${ }^{260} \mathrm{Lr}$. However, the data were all examined for time correlations characteristic of the ${ }^{223}$ Ac decay chain and its contribution was found to be negligivle.

In order to correct for gas jet yield, chemical yield, detector efficiency, beam intensity, and other possible variables, the yield of $260 \mathrm{Lr}$ was obtained relative to the amounts of $30-\mathrm{ml}{ }^{250} \mathrm{Fm}, 3.2-\mathrm{h}$ ${ }^{254} \mathrm{Fm}$, or $25-\mathrm{h}^{252} \mathrm{Fm}$ produced in each run. The yielas of these $\mathrm{Fm}$ isotopes were determined from separate one-hour irradiations carried out just before or after the fast chemistry runs and under the same conditions. The recoiling products were caught in $7-2 \mathrm{mg} / \mathrm{cm}^{2} \mathrm{Au}$ foil. The experimental arrangement is described in a previous paper. ${ }^{15}$ The Au foil was dissolved in conc. $\mathrm{HCl}$ and a few drops of $\mathrm{HNO}_{3}$ containing $241_{\mathrm{Am}}$ tracer for yield determination. The resulting solution was passed 
through an anion exchange res in column to remove the $\mathrm{Au}$ and then electroplated. ${ }^{16}$ Alpha spectroscopic measurements were performed to measure the production cross sections of the $\mathrm{Fm}$ isotopes.

\section{RESULTS AND DISCUSSION}

Recoiling reaction products were extracted with TTA from buffer solutions of $\mathrm{pH} 1.86,2.33,2.67,3.00,3.15,3.5,4.0,4.5,5.0$, and 5.5. The number of events of $260 \mathrm{Lr}$ produced per experiment can be calculated relative to the observed production of ${ }^{250} \mathrm{Fm},{ }^{254} \mathrm{Fm}$, or $252,255 \mathrm{Fm}$ whose effective cross sections for the target composition were determined for the conditions of these experiments. (The contribution from ${ }^{249} \mathrm{Cf}$ must be considered since ${ }^{249}$ BK decays with a $330-\mathrm{d}$ half life to ${ }^{249} \mathrm{Cf.}$ ) In about one hundred 6- to 10-minute collections and separations, 27 events attributable to ${ }^{260} \mathrm{Lr}$ were detected. Neither the $3-\mathrm{m} 260 \mathrm{Lr}$ nor the $\mathrm{Fm}$ isotopes was extracted at $\mathrm{pH} 1.86$. The extraction of the 8.03-MeV, 3-m activity was nearly complete by $\mathrm{pH} 3.15$. This shows that it exhibits the same extraction behavior as observea ${ }^{8}$ previously for $28-\mathrm{s}{ }^{256} \mathrm{Lr}$ and the trivalent heavy actinides $\mathrm{Am}, \mathrm{Cm}, \mathrm{Cf}$, and $\mathrm{Fm}$. Its behavior differs from that extraction of divalent No whose extraction does not begin until pH 4 and is not complete until about pH 5 . The fact that no $8.03-\mathrm{MeV}, 3-\mathrm{m}$ alpha events were extracted at $\mathrm{pH} 1.86$ shows that $260 \mathrm{Lr}$ is not in a tetravalent oxidation state. From these experiments, we conclude that the chemistry of the $3-\mathrm{m}, 8.03-\mathrm{MeV}$ alpha emitter is consistent with that of Lr in the trivalent oxidation state.

The cross section for production of ${ }^{260} \mathrm{Lr}$ via the ${ }^{249} \mathrm{BK}\left({ }^{18} 0, \alpha 3 n\right)$ reaction at $101 \mathrm{MeV}$ was measured in similar TTA extractions conducted at a pH of 2.9 to avoid possible contamination from No. About 45 alphas from ${ }^{260}$ Lr were detected. The yield for the 
procedure was obtained from the $\mathrm{Fm}$ isotopes and a cross section of $8.3 \pm 1.7^{\circ} \mathrm{nd}$ was calculated for ${ }^{260} \mathrm{Lr}$. The half-life for these events was consistent with the $3.0 \pm 0.5-\mathrm{m}$ half-life reported by Eskola et al. ${ }^{12}$

The attempts to reduce $\operatorname{Lr}(I I I)$ to a lower oxidation state with $\mathrm{NH}_{2} \mathrm{OH} \cdot \mathrm{HC} 1$ were unsuccessful. In a series of 24 experiments, no events attributable to $260 \mathrm{Lr}$ were observed in the $0.3 \mathrm{M} \mathrm{HCl} / 0.06 \mathrm{M} \mathrm{NH}_{2} \mathrm{OH} \cdot \mathrm{HCl}$ fraction from the HDEHP column which contained the species with lower oxidation states. Four events attributable to ${ }^{260} \mathrm{Lr}$ were observed in the $3 \mathrm{MHCl}$ fraction containing the heavy trivalent actinides. Al though the potential for the oxidation of $\mathrm{NH}_{2} \mathrm{OH} \cdot \mathrm{HCl}$ to $\mathrm{N}_{2}$ is $-1.87 \mathrm{~V}$, the $k$ inetics are known to be slow. A check of our data showed that 254,255 Md was not reduced even though its standard reduction potential 17 is on $1 y-0.1$ to $-0.2 \mathrm{~V}$, thus confirming that a time of $20 \mathrm{~s}$ at $80^{\circ} \mathrm{C}$ was insufficient to accomplish the reduction. 0ther strong reducing agents whose kinetics are faster will have to be used, or perhaps studies with the recentiy discovered ${ }^{18}$ Ionger-lived isotopes $261,262 \mathrm{Lr}$ can be performed.

In the initial HIB elutions from cation exchange res in columns, Yb and Er tracers were used and it was found that the $3-m^{260} \mathrm{Lr}$ elutea nearly with the Er tracer. In order to avoid any possible problems due to the finite (about $0.1 \mu \mathrm{g}$ ) mass of the Er tracer, a series of elution experiments was conducted using only $\mathrm{Tm}$ and Ho tracers to bracket the $\mathrm{Er}$ (Lr) position. In 18 such experiments, seven alpha events attributable to $3-m{ }^{260} \mathrm{Lr}$ were detected. (The most probable half-life for these 8.03-MeV alpha events is $2.7+1.7 \mathrm{~m}$, consistent with the value of $3.0 \pm 0.5 \mathrm{~m}$ reported earlier by Eskola et al. ${ }^{12}$.) The elution position of each of these $8.03-\mathrm{MeV}$ alpha events was compared with the elution positions of the Tm and Ho tracers. (See Fig. 2.) From this infor- 
mation, an ionic radius was calculated for each $L r$ event, and the average Lr radius was found to be $0.0005 \pm 0.0003 \mathrm{~nm} \mathrm{larger} \mathrm{than} \mathrm{that} \mathrm{of} \mathrm{Er.} \mathrm{If}$ the ionic radius of $\mathrm{Er}$ is taken to be $0.0881 \mathrm{~nm}$ as measured by Templeton and Dauben ${ }^{5}$, then the ion ic radius of $\mathrm{Lr}$ is $0.0886 \pm 0.0003 \mathrm{~nm}$.

Other experiments have shown that Md (101) elutes very close to the Ho position, implying that the ionic radius of Md is similar to that of Ho, or about $0.0894 \mathrm{~nm}$. This gives a difference between the Md ${ }^{3+}$ radius and the $\mathrm{Lr}^{3+}$ radius of on ly $0.001 \mathrm{~nm}$, comparable with the usual difference between ionic radii of adjacent lanthanide or act inide elements, even though there is a difference of $2 Z$ between Md and Lr. This is much smaller than the 22 separation of $0.0021 \mathrm{~nm}$ for the analogous lanthanide ions, $\mathrm{Tm}^{3+}$ and $\mathrm{Lu}^{3+}$, at the end of the lanthanide series. Due to these apparently very close values for the ionic radii of the last three actinides, it becomes especially important to measure the ion ic radius of the $\mathrm{No}^{3+}$ ion. Because No is most stable in aqueous solution in the divalent state, the HIB method cannot be used as it will not work under the strongly oxidizing and acidic conditions necessary to keep No in the $3+$ state. Perhaps the HDEHP chromatographic column technique can be adapted for obtaining informatio:1 about the ionic radius of No (1II) based on its elution position relative to other actinides and the lanthanides.

Acknowledgements: The authors are indebted to the Division of Chemical Sciences, Office of Basic Energy Sciences, U.S. Department of Energy, for mak ing the ${ }^{249} \mathrm{Bk}$ available through the transpluton ium element production facilities at the Oak Ridge National Laboratory. We wish to thank the staff and crew of the LBL 88-Inch Cyclotron for providing the ${ }^{18} 0$ beams and technical support. *S. Cai was a visiting scientist from the Radioisotope Division, Institute of Atomic energy, $\mathrm{P}$. 0. Box 275(66), Beijing, China. This work was supported by the Director, Office of Energy Research, Division of Nuclear Physics of the Office of High Energy and Nuclear Physics of the U.S. Departnent of Energy under Contract No. DE-AC03-76SF00098. 


\section{References}

1. 0. L. KELLER, Jr., Radiochim. Acta, 37 (1984) 169.

2. R. J. SILVA, T. SIKKELANd, M. NURMiA, A. GHIORSO, E. K. HULET, J. Inorg. Nucl. Chem., 31 (1969) 3405.

3. L. BREWER, J. Opt. Soc. Am. 61 (1971) 1101.

4. J.-P. DESCLAUX, B. FRICKE, J. Phys. 41 (1980) 943.

5. 0. H. TEMPLETON, C. H. DAUBEeN, J. Am. Chem. Soc., 76 (1954) 5237.

6. S. GOLDMAN, L. R. MORSS, Can. J. Chem., 53 (1975) 2695.

7. S. G. BRATSCH, J. J. LAGOWSKI, J. Phys. Chem. 90 (1986) 307.

8. R. J. SILVA, T. SIKKELAND, M. NURMIA, A. GHIORSO, Inorg. Nucl. Chem. Lett. 6, (1970) 733.

9. G. T. SEABORG, Chem. \& Eng. News, 23 (1945) 2190.

10. G. R. CHOPPIN, R. J. SILVA, J. Inorg. Nucl. Chem. 3 (1956) 153.

11. H. L. SMITH, D. C. HOFFMAN, J. Inorg. Nucl. Chem. 3 (1956) 243.

12. K. ESKOLA, P. ESKOLA, M. NURMIA, A. GHIORSO, Phys. Rev, C, 4 (1971) 632 .

13. G. Müllen, D.C. AUMANN, Nucl. Instr. Meth., 128 (1975) 425.

14. E. P. HORWITZ, C. A. A. BLOOMQUIST, D. J. HENDERSON, J. Inorg. Nucl. Chem., 31 (1969) 1149 .

15. D. LEE, H, VON GUNTEN, B. JACAK, M. NURMIA, Y. -F. LIU, C. LUO, G. T. SEABORG, D. C. HOFFMAN, Phys. Rev. C, 25 (1982) 286.

16. D. C. HOFFMAN, in LOS Alamos Scientific Laboratory Report LA-1721, 4 th ed. (1982) p. 109.

17. E. K. HULET, Radiochim. Acta 32 (1983) 7.

18. R. W. LOUGHEED, Private Communication (1987). 
Figures

Figure 1. Decay sequence from $223 \mathrm{AC}$.

Figure 2. Schematic of HIB elution showing Lr position.

\section{DISCLAIMER}

This report was prepared as an account of work sponsored by an agency of the United States Government. Neither the Uniled States Government nor any agency thereof, nor any of their emptoyoes, makes any warranty, express or implied, or assumes any legal liability or responsibility for the accurtcy, completeness, or usefulness of any information, apparatus, product, or process disclosed, or represents that its use would nut infringe privately owned rights. Reference herein to any specific commercial product, process, or service by trade name, trademark, manufacturer, or otherwise does not necessarily constitute or imply its endorsement, recornmendation, or favoring by the United States Government or any agency thereof. The views and opinions of authors expressed herein do not necessarily stute or reflect those of the United States Government or any agency thereof. 


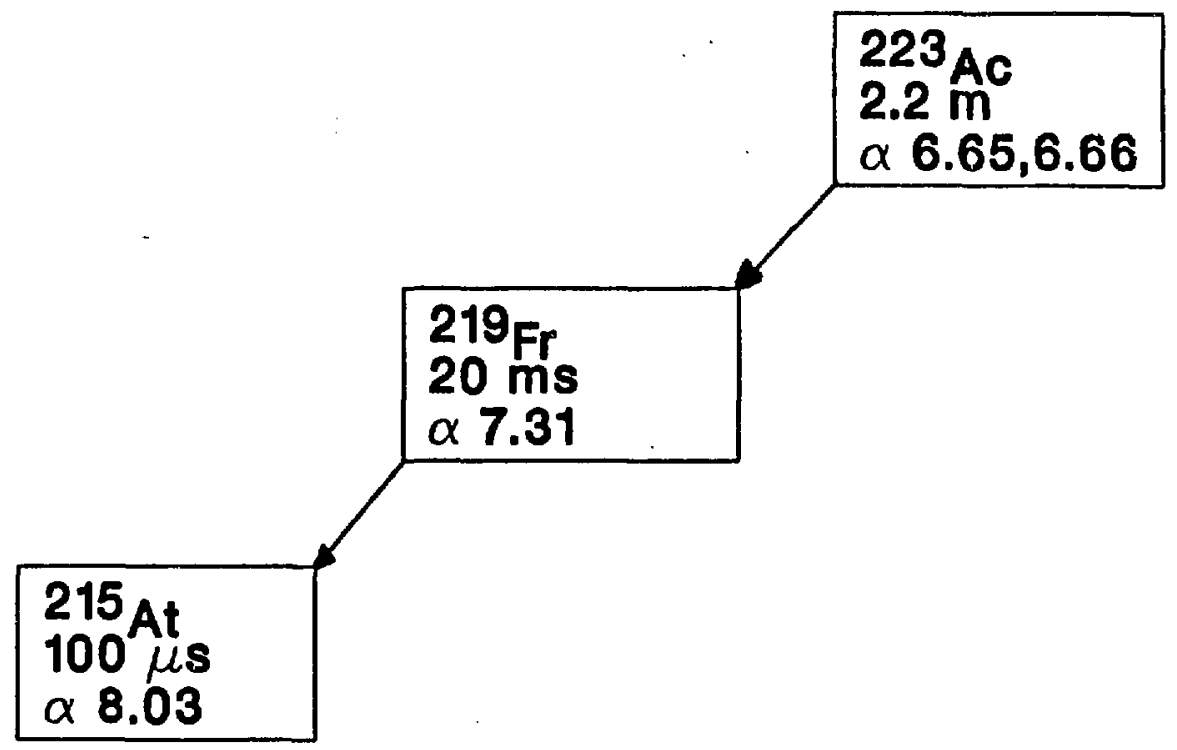

XBL. 874-1766

Fig. 1. Decay sequence from ${ }^{223} \mathrm{AC}$ 


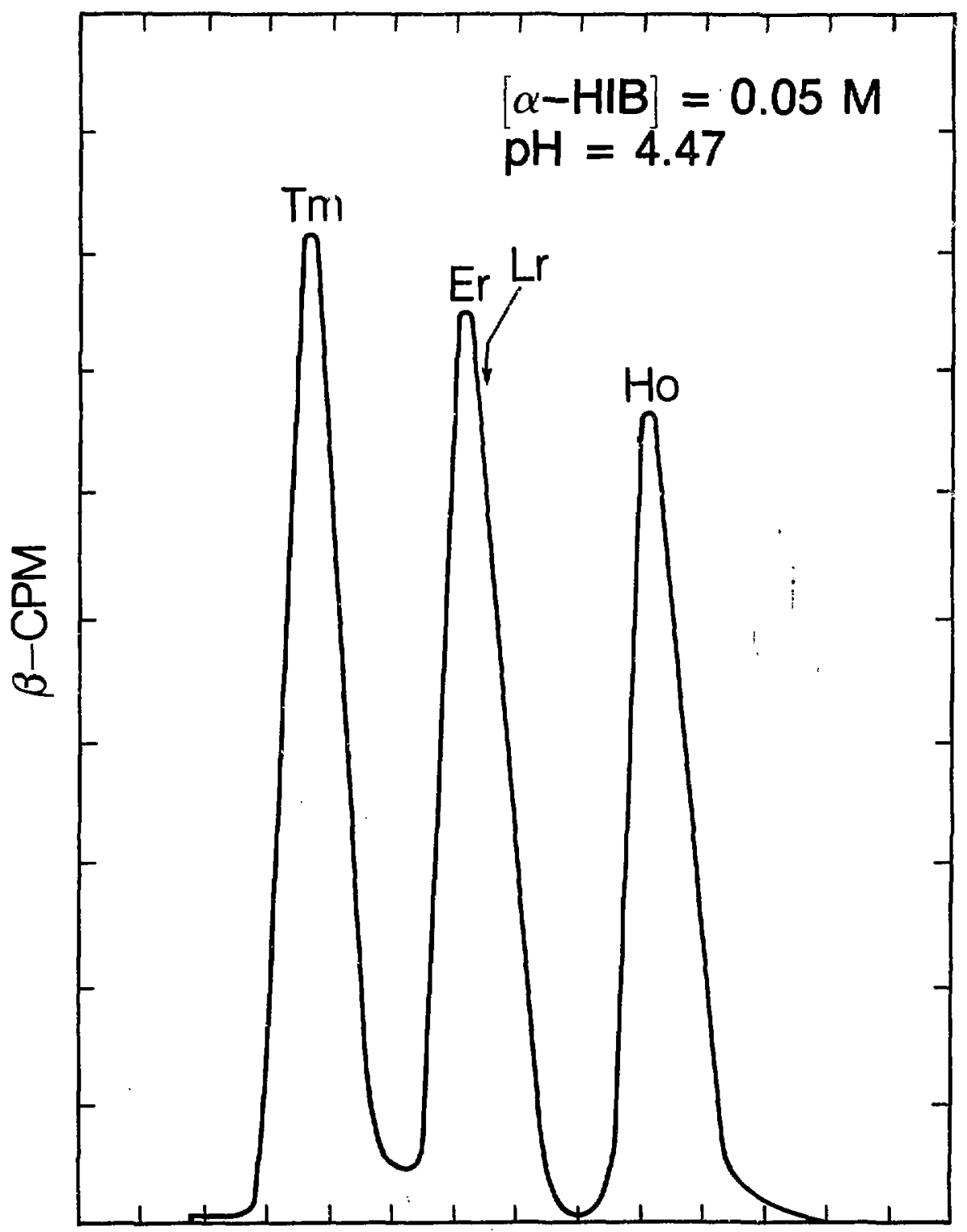

XBL $873 \cdot 1270$

Fig. 2. Schematic of HIB elution showing Lr position 